\title{
Experimental Investigation for Tensile Performance of GFRP-Steel Hybridized Rebar
}

\author{
Dong-Woo Seo, Ki-Tae Park, Young-Jun You, and Sang-Yoon Lee \\ Structural Engineering Research Institute (SERI), Korea Institute of Civil Engineering and Building Technology (KICT), \\ Goyang 10223, Republic of Korea \\ Correspondence should be addressed to Dong-Woo Seo; dwseo@kict.re.kr
}

Received 23 October 2015; Accepted 14 January 2016

Academic Editor: Francesco Delogu

Copyright (C) 2016 Dong-Woo Seo et al. This is an open access article distributed under the Creative Commons Attribution License, which permits unrestricted use, distribution, and reproduction in any medium, provided the original work is properly cited.

Tensile performance of the recently developed "FRP Hybrid Bar" at Korea Institute of Civil Engineering and Building Technology (KICT) is experimentally evaluated by the authors. FRP Hybrid Bar is introduced to overcome the low elastic modulus of the existing GFRP bars to be used as a structural member in reinforced concrete structures. The concept of material hybridization is applied to increase elastic modulus of GFRP bars by using steel. This hybridized GFRP bar can be used in concrete structures as a flexural reinforcement with a sufficient level of elastic modulus. In order to verify the effect of material hybridization on tensile properties, tensile tests are conducted. The test results for both FRP Hybrid Bar and the existing GFRP bars are compared. The results indicate that the elastic modulus of FRP Hybrid Bar can be enhanced by up to approximately 250 percent by the material hybridization with a sufficient tensile strength. To ensure the long-term durability of FRP Hybrid Bar to corrosion resistance, the individual and combined effects of environmental conditions on FRP Hybrid Bar itself as well as on the interface between rebar and concrete are currently under investigation.

\section{Introduction}

One of shortcomings of steel rebar for reinforced concrete (RC) structures is a corrosion problem, and fiber-reinforced polymer (FRP) has been considered as an alternative. The corrosion of steel rebar is essentially a material problem, not a structural problem, for the RC structures. Researches for developing rebars composed of FRP were initiated in 1960s and this made progress [1]. FRP is composed of fibers and resin, and it provides outstanding features, including noncorrosiveness, high tensile strength, fatigue-resistance, light weight, nonmagnetism, nonconductivity, and easy treatment. Owing to these features, FRP can be utilized not only to waterfront structures, those being exposed to a highly corrosive environment, but also to concrete structures exposed to deicing agent, such as bridge decks [2].

In USA, Canada, and Europe active researches on FRP have been engaged. Some achievements have been made and products have been restrictedly applied in construction sites (e.g., commercially available GFRP bars shown in Figure 1). In Korea, a glass fiber-reinforced polymer (GFRP) bar was developed and introduced at the Korea Institute of Civil Engineering and Building Technology (KICT) as shown in Figure $2[3,4]$.

However, FRP rebars are still restrictedly utilized in the construction site. Despite of its numerous advantages, the reasons for a limited use of the FRP rebar as a structural reinforcement are due to its low modulus of elasticity, the brittle failure type, and its high cost compared to the traditional reinforcing steel. Owing to these shortcomings, hybrid FRP bars were introduced to enhance the elastic modulus and to improve the brittle failure type [4-23].

"FRP Hybrid Bar" was developed at KICT using glass fiber and steel that compensates for shortcomings of GFRP rebar. The hybridization of GFRP rebar has been also investigated by other researchers [4-23]. An experimentation of tensile properties was conducted and the results were explained in this study. The purpose of this study was to identify a feasible material hybridization of GFRP with steel through the experimentation and to potentially use FRP Hybrid Bar to RC structures that are built in the highly corrosive environment with its preferable corrosion resistance. 


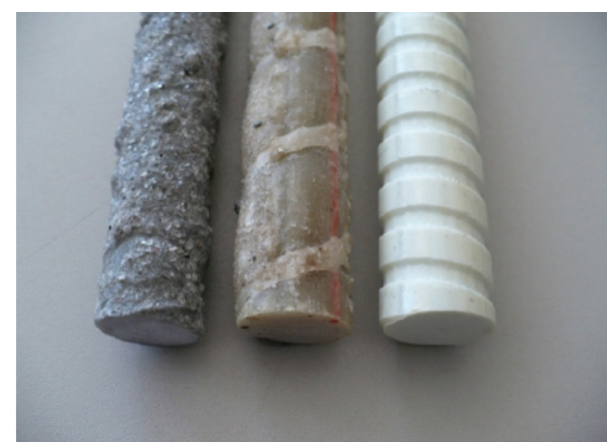

Figure 1: Pultrall V-Rod, Aslan 100, and Schöck ComBAR (left to right) [5].

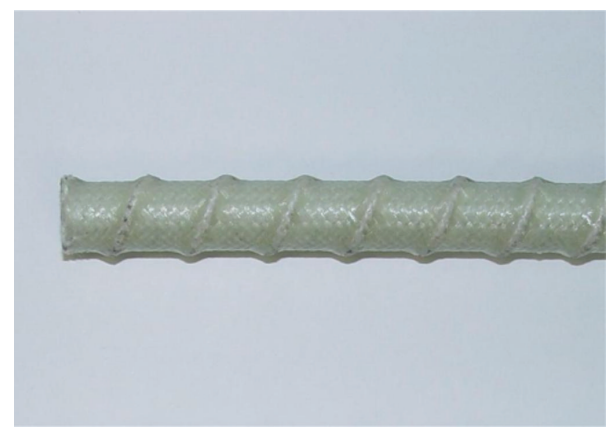

FIGURE 2: KICT GFRP bar [3].

This study presents the results of an experimental evaluation of FRP Hybrid Bar for tensile properties by comparing with fully GFRP bars. The FRP Hybrid Bar is designed and manufactured by combining the two different materials, including glass fibers and steel. Both vinylester and unsaturated polyester are utilized as resin materials for glass fibers. For comparison purposes, the existing GFRP rebar, developed and fabricated at KICT $[3,25,26]$, and two commercially available GFRP bars (Aslan 100 and V-Rod $[27,28]$ ) are also tested.

\section{Development of "FRP Hybrid Bars"}

2.1. "FRP Hybrid Bar" Design. This study introduces "FRP Hybrid Bar" (FHB) and this FHP is developed to overcome the low elastic modulus of GFRP bar by hybridizing with steel. Three types of FHP and one GFRP bar are taken into consideration in this study: (a) a fully GFRP bar; (b) GFRP crust with a steel rod in the core; (c) GFRP crust with steel wires dispersed over the cross section; and (d) GFRP crust with a steel rebar in the core. FHB samples are fabricated as three cases categorized by different diameters, equal to approximately $13 \mathrm{~mm}, 16 \mathrm{~mm}$, and $19 \mathrm{~mm}$. The diameter for the FHB does not include the height of the deformers. Each case is indicated in this study as D13, D16, and D19 with $13 \mathrm{~mm}, 16 \mathrm{~mm}$, and $19 \mathrm{~mm}$, respectively.

Figure 3 describes the details of three cross section types of FHB and a fully GFRP bar investigated in this study, Type A through Type D. The surface of all types of the bar is braided, and the deformer is generated while in the process of pultrusion.

The list of specimens for the tensile test is presented in Table 1. A total of 140 specimens are tested. Table 1 is subcategorized by diameter (i.e., D13, D16, and D19), cross section type (i.e., Type A, Type B, Type C, and Type D), and steelto-GFRP volume ratio (herein called steel volume fraction). Type A denotes fully GFRP bar as a reference case, including two commercially available GFRP bars (i.e., Aslan 100 and VRod, [27, 28]) and a GFRP rebar developed at Korea Institute of Civil Engineering and Building Technology (herein called "KICT bar" [8]).

The various steel volume fractions to cross section area are parameterized to evaluate the effect of steel hybridization on tensile performance. For example, specimen number 4 in Table 1 "FHB-D13-D4-B" reads as "(FRP Hybrid Bar)-(the outer diameter)-(a steel rod or a rebar diameter)-(the cross section type)." As a second example, specimen number 8 "FHP-D13-D2-4-C" reads as "(FRP Hybrid Bar)-(the outer diameter)-(a wire diameter)-(the number of inserted wires)(the cross section type)."

2.2. "FRP Hybrid Bar" Fabrication. Pultrusion, braiding, and filament winding are the typical methods for the manufacture of FRP. Pultrusion is a continuous manufacturing process producing unidirectional members with a constant cross section and is known as the most economic and rapid method for the production of prestress tendons and reinforcing bars. This makes it the most adopted method for the manufacture of FRP rebar [29, 30].

The bond performance with concrete constitutes the utmost performance required for the FRP member to fulfill its role inside concrete. Even if the pultrusion offers the advantage of continuously producing members with constant cross section, an additional process is necessary to achieve the bond performance with concrete since the produced member exhibits smooth surface [31]. In order to solve this problem, a process by combining pultrusion and braiding has been proposed by Ko et al. [32]. This process called "braidtrusion" executes additional braiding during the pultrusion process so as to form a net-like skin at the surface of the reinforced fiber bundle. The braidtrusion bears thus the continuous manufacturing and the preservation of a constant cross section featured by the pultrusion together with the rough surface or skin featured by the braiding. However, the braidtruded FRP rebar experiences loss of its tensile performance due to the voids generated in the section by the air entrained during the resin impregnation of the relatively loose fiber bundles constituting the core of the rebar [33].

In order to reduce the voids inside the section, KICT [34] proposed an improved braidtrusion process as shown in Figure 4. While preserving the advantages of the previous braidtrusion, this modified process improves the tensile performance through the reduction of the voids and the enhancement of the fiber arrangement by introducing a definite prestress in the fiber to achieve the reinforced fiber bundles and the deformation. The specimens of FHP tested in this study are manufactured using this process. 
TABLE 1: List of specimens for tensile test.

\begin{tabular}{|c|c|c|c|c|c|c|}
\hline Number & Diameter & Name & Type & Steel-to-GFRP ratio (\%) & Quantity (EA) & Length $(\mathrm{mm})$ \\
\hline 1 & \multirow{12}{*}{ D13 } & KICT-D13 & \multirow{3}{*}{ A } & 0.0 & 6 & 1,500 \\
\hline 2 & & Aslan-D13 & & 0.0 & 3 & 1,500 \\
\hline 3 & & V-Rod-D13 & & 0.0 & 3 & 1,500 \\
\hline 4 & & FHB-D13-D4-B & \multirow{4}{*}{ B } & 9.2 & 6 & 1,500 \\
\hline 5 & & FHB-D13-D7-B & & 29.9 & 6 & 1,500 \\
\hline 6 & & FHB-D13-D9-B & & 51.0 & 6 & 1,500 \\
\hline 7 & & FHB-D13-D11-B & & 76.2 & 6 & 1,500 \\
\hline 8 & & FHB-D13-D2-4-C & \multirow{4}{*}{$\mathrm{C}$} & 9.8 & 4 & 1,500 \\
\hline 9 & & FHB-D13-D2-13-C & & 31.8 & 4 & 1,500 \\
\hline 10 & & FHB-D13-D2-23-C & & 57.0 & 6 & 1,500 \\
\hline 11 & & FHB-D13-D2-29-C & & 70.3 & 4 & 1,500 \\
\hline 12 & & FHP-D13-D10-D & $\mathrm{D}$ & 57.2 & 6 & 1,500 \\
\hline 13 & \multirow{7}{*}{ D16 } & KICT-D16 & A & 0.0 & 6 & 2,200 \\
\hline 14 & & FHB-D16-D2-7-C & \multirow{4}{*}{$\mathrm{C}$} & 10.9 & 4 & 2,200 \\
\hline 15 & & FHB-D16-D2-23-C & & 36.9 & 6 & 2,200 \\
\hline 16 & & FHB-D16-D2-41-C & & 60.2 & 6 & 2,200 \\
\hline 17 & & FHB-D16-D2-47-C & & 70.1 & 4 & 2,200 \\
\hline 18 & & FHP-D16-D10-D & \multirow{2}{*}{$\mathrm{D}$} & 36.6 & 6 & 2,200 \\
\hline 19 & & FHP-D16-D13-D & & 63.2 & 6 & 2,200 \\
\hline 20 & \multirow{7}{*}{ D19 } & KICT-D19 & $\mathrm{A}$ & 0.0 & 6 & 2,900 \\
\hline 21 & & FHB-D19-D2-23-C & \multirow{3}{*}{$\mathrm{C}$} & 25.0 & 6 & 2,900 \\
\hline 22 & & FHB-D19-D2-41-C & & 42.3 & 6 & 2,900 \\
\hline 23 & & FHB-D19-D2-63-C & & 66.3 & 6 & 2,900 \\
\hline 24 & & FHP-D19-D10-D & \multirow{3}{*}{$\mathrm{D}$} & 24.7 & 6 & 2,900 \\
\hline 25 & & FHP-D19-D13-D & & 45.9 & 6 & 2,900 \\
\hline \multirow[t]{2}{*}{26} & & FHP-D19-D16-D & & 67.9 & 6 & 2,900 \\
\hline & & & & & 140 & \\
\hline
\end{tabular}

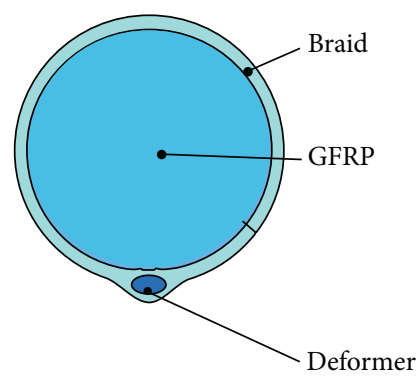

(a)

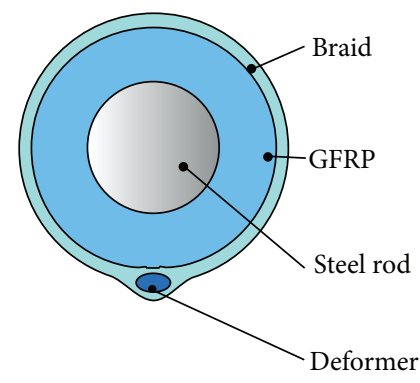

(b)

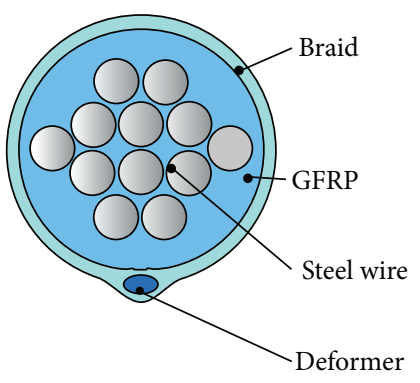

(c)

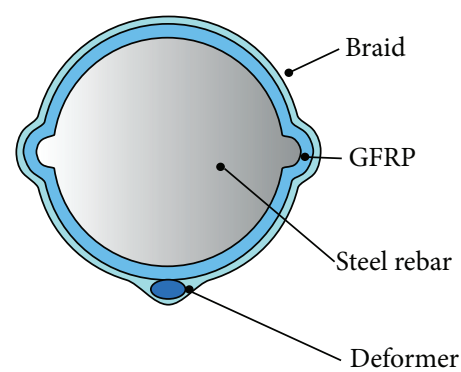

(d)

FIGURE 3: Cross section types of "FRP Hybrid Bar" [24]: (a) Type A (the KICT GFRP bar [8]); (b) Type B (GFRP with a steel rod); (c) Type C (GFRP with steel wires); and (d) Type D (GFRP with a steel rebar). 
TABLE 2: Material properties for FRP Hybrid Bar.

\begin{tabular}{lccc}
\hline Material & Model name & Elastic modulus (GPa) & Tensile strength (MPa) \\
\hline Resin 1 & HETRON 922 & 3.2 & 86 \\
Resin 2 & Dion-9100 & 3.2 & 79 \\
Core fiber & SE1200 & 81 & 2,600 \\
Deformation fiber & Nylon & 75 & 70 \\
\hline Steel rod & KS D3510 & 200 & $1,180 \sim 1370$ \\
Steel wire & KS D3510 & 200 & $1,270 \sim 1470$ \\
Steel rebar & KS D3504 & 200 & 400 \\
\hline
\end{tabular}

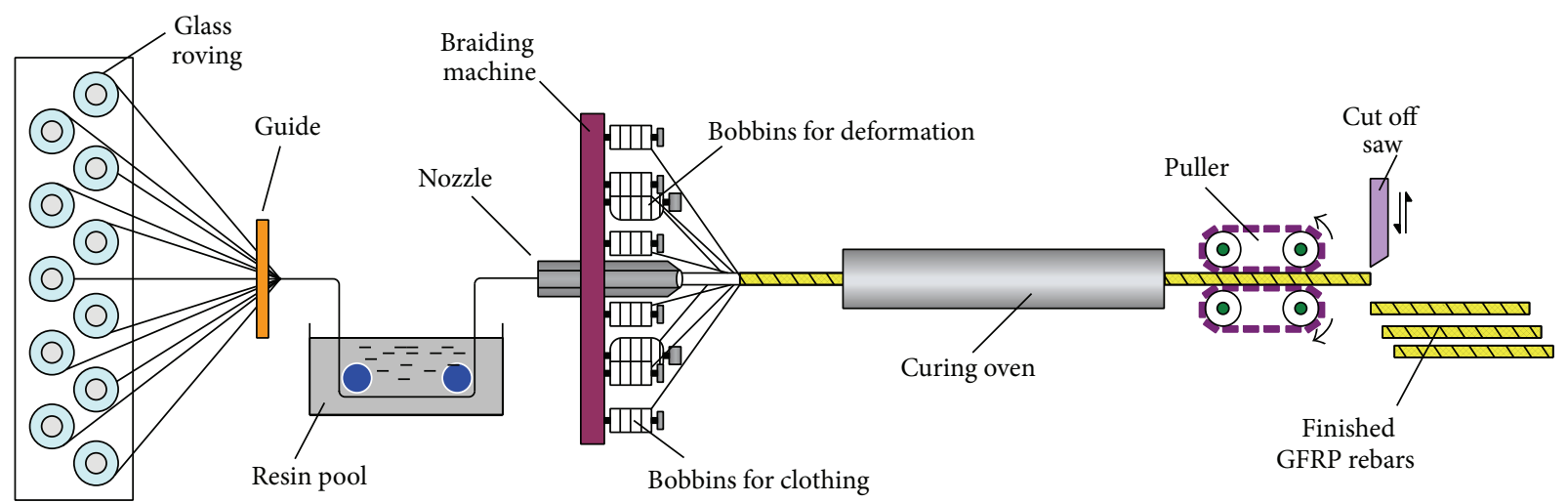

FIGURE 4: Modified braidtrusion process [24].

FRP Hybrid Bar is fabricated by mixing E-glass fiber (SE1200-2200TEX, Owens Corning, Korea [35]) and unsaturated polyester resins that are DION-9100 and HETRON-922. Polyamide-based nylon fiber was used for the formation of the protuberance at the surface of the deformed rebar in order to secure mechanical bonding with concrete. The properties of the adopted materials as well as steel inserts for material hybridization are arranged in Table 2. Vinylester and unsaturated polyester are known as effective resins for the pultrusion process of fabrication because they offer an economical advantage, low viscosity, and rapid hardening. For hardening $90^{\circ} \mathrm{C}$ of heat was applied to the bar.

Figure 5(a) shows the conceptual view of braidtrusion process and Figure 5(b) depicts a braiding machine developed at KICT [34]. Figure 5(c) shows a guide installed to control the position of the steel wires in this case (or other steel inserts for different FHB types) spread over the cross section.

Figure 6 depicts the cross section details of final FHP products, Type A Type D, after finishing the braidtrusion process.

\section{Experiments}

3.1. Specimen Preparation. The tensile tests were carried out in accordance with ASTM D3916 [36]. The dimension of the specimens was as follows: (a) for D13 specimens, the total length was $1,500 \mathrm{~mm}$ and the gauge length $L$ was $450 \mathrm{~mm}$; (b) for D16 specimens, the total length was 2,200 $\mathrm{mm}$ and the gauge length $L$ was $700 \mathrm{~mm}$; and (c) for D19 specimens, the total length was $2,900 \mathrm{~mm}$ and the gauge length $L$ was $1,000 \mathrm{~mm}$. The minimum gauge length was required to be at least 40 times greater than the diameter of the bar, specified in CSA standards [37, 38]. A schematic representation of the specimen is shown in Figure 7. A load cell and linear variable differential transducers (LVDTs) were attached in the Location 1 and a strain gauge was placed in the Location 2.

Strain gauges were provided from KMTL (http://www .kmtl.co.kr/bbs/index.php), with a model name of "FLA-5-115L." This type of strain gauge is normally used for steel tests. Figure 8 shows the process of the strain gauge attachment. The surface of the bar was cleaned with an alcohol cleaner and then the gauge was attached to the bar in the longitudinal direction.

To prepare the specimens for tensile tests, steel grip adapters were designed and fabricated in accordance with CSA standards $[37,38]$. The thickness of steel grip adapter was varied from $4.9 \mathrm{~mm}$ to $7.1 \mathrm{~mm}$ based on the requirements $[37,38]$. Two stoppers with a hole perforated on their center were disposed at both ends of each steel tube so as to insert and position the FHB to the center. The grip length of $400 \mathrm{~mm}$ was used particularly for D13 specimens. An anchor and nonshrinkage mortar were filled into the grip adapters and cured for a week to obtain the compressive strength equal to approximately $60 \mathrm{MPa}$. The surface of FHB was coated with iron shavings to ensure enough bonding strength between FHB and the steel grip adapter. Iron shavings were attached using a bonding adhesive as shown in Figure 9. Figure 10 shows the completed specimens for tensile tests.

3.2. Test Setup and Measuring Devices. Figure 11 shows the test setup and UTM with a capacity of $1,000 \mathrm{kN}$ and the maximum stroke length of $500 \mathrm{~mm}$ used for tensile test. The LVDT 


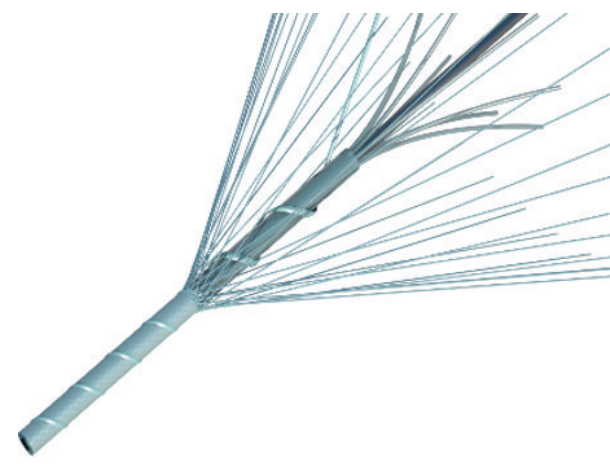

(a)

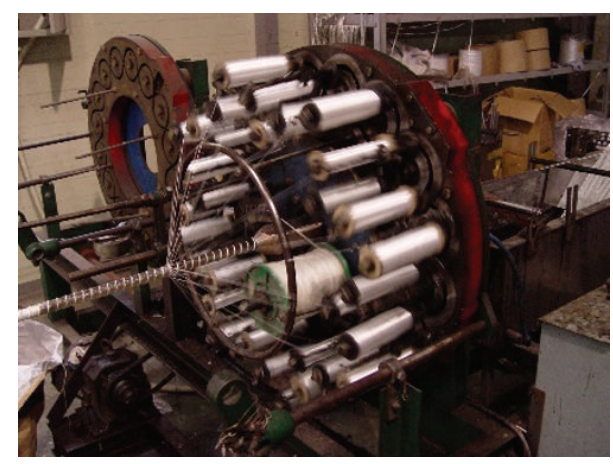

(b)

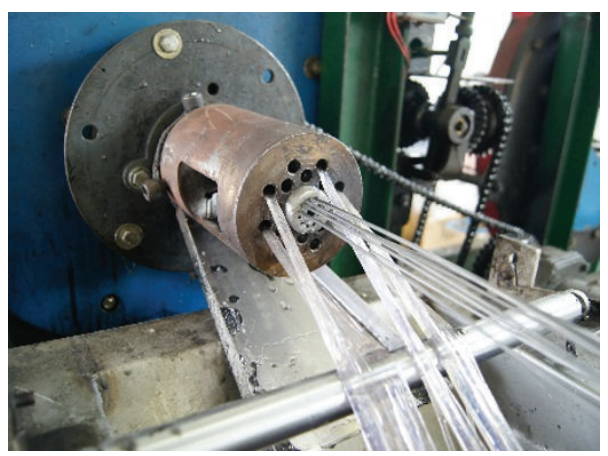

(c)

FIGURE 5: The braidtrusion process [24]: (a) the conceptual configuration; (b) the braidtrusion machine; and (c) the insertion of steel wires.

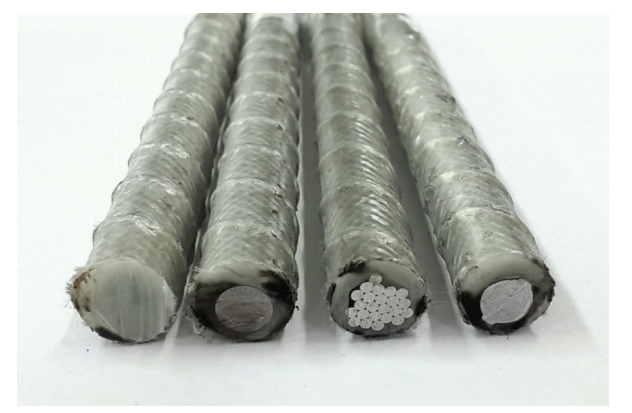

FIGURE 6: The cross section view of FRP Hybrid Bar.

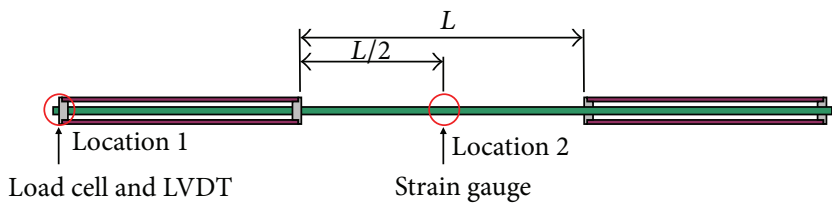

FIgURE 7: Sensor locations [24].

was used to measure the displacement and slip quantities under axial loads. The LVDT was installed on the bar at its free end and measures the relative displacement between the center and its free end of the bar.

The specimens were fixed both at the top and at the bottom of the steel grip adapters. A screw was disposed at one end of the steel grip adapter constituting the grip so as to fix the specimen with a nut and both ends of the grip were subject to tension as shown in Figure 11. The applied loading rate was determined in accordance with CSA standards $[37,38]$ equal to $5 \mathrm{~mm} / \mathrm{min}$ for D13 and D16 specimens and $2 \mathrm{~mm} / \mathrm{min}$ for D19 specimens. The load and corresponding strains were collected using a data logger.

\section{Test Results}

4.1. Tensile Behavioral Characteristics. For the tensile test, a total of 140 specimens, described in Table 1, are tested. The tensile strength of the specimens can be calculated by dividing the measured maximum load over the cross-sectional area of FRP Hybrid Bar $\left(A_{\text {hybrid }}\right)$. The elastic modulus of FRP Hybrid Bar $\left(E_{\text {hybrid }}\right)$ can be given by the following expression as recommended in [37]:

$$
E_{\text {hybrid }}=\frac{\left(P_{1}-P_{2}\right)}{\left(\varepsilon_{1}-\varepsilon_{2}\right) A_{\text {hybrid }}} .
$$

In (1) $P_{1}$ and $P_{2}$ are the applied loads corresponding to $50 \%$ and $25 \%$ of the ultimate load, respectively, and $\varepsilon_{1}$ and $\varepsilon_{2}$ are the corresponding strains.

Table 3 summarizes the result of tensile tests for D13 FRP Hybrid Bar. Most of the specimens failed in the area of the gauge length. 12 cases were tested associated with 4 different types and with various steel-to-GFRP volume ratios explained in Section 2.1.

The average (Aver.) values, coefficient of variation $(\mathrm{CoV})$, and improvements (Imp.) of experimental results for both 

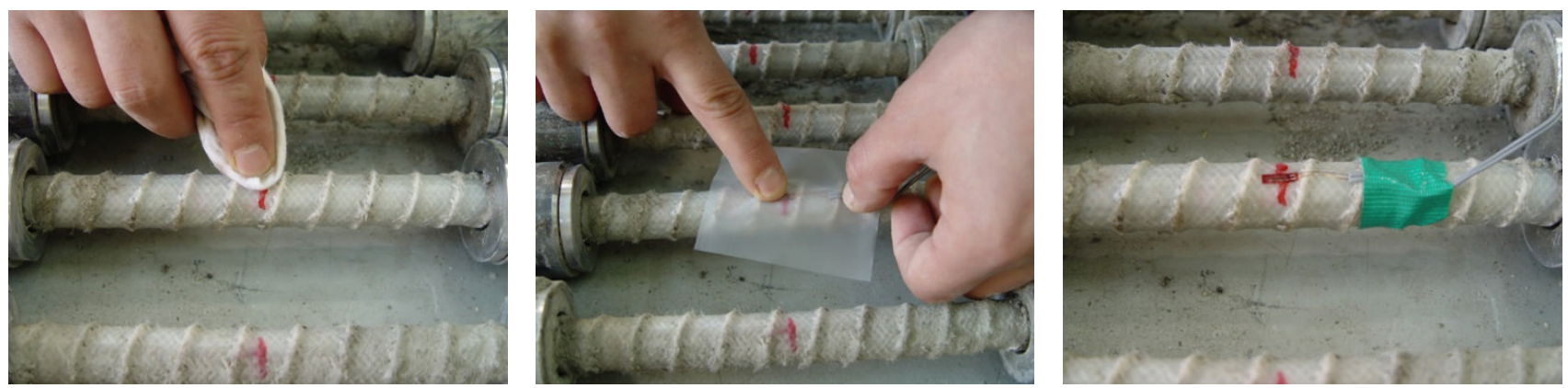

FIGURE 8: The strain gauge attachment.
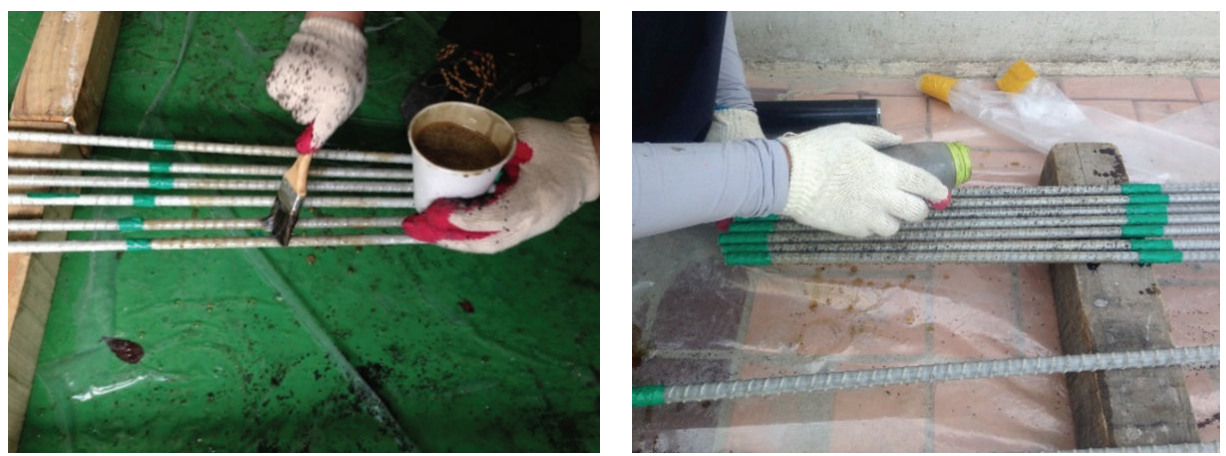

FIGURE 9: Coating with iron shavings.

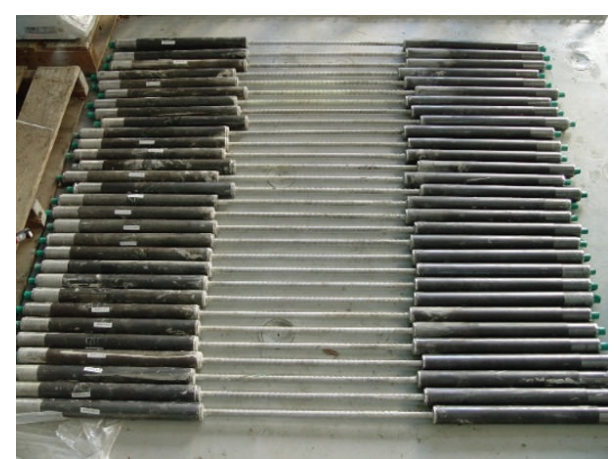

FIgURE 10: Preparation of gripping system [24].

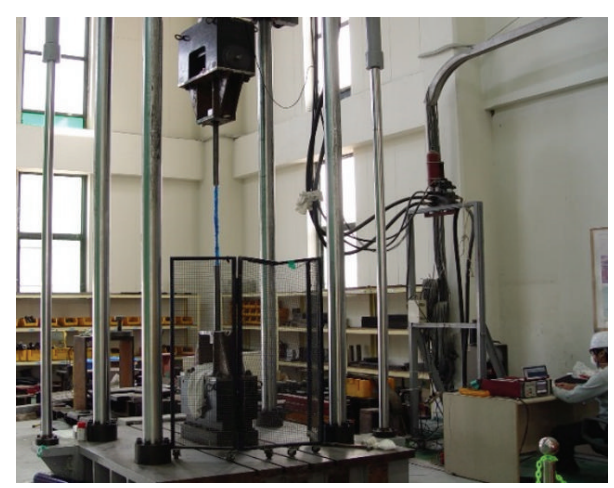

Figure 11: Tensile test setup. elastic modulus and tensile strength are presented in Table 3. $\mathrm{CoV}$ was calculated as standard deviation divided by an average value of the repeated tests. The effects of material hybridization on both elastic modulus and tensile strength were also investigated in terms of improvements (Imp.). The improvement is a relative value normalized to the value of nonhybrid GFRP bar (i.e., number 3) as a reference case. For example, case number 4 was improved by $70.2 \%$ in elastic modulus and $57.0 \%$ in maximum tensile strength, respectively, in comparison with case number 3. Elastic modulus tends to increase up to $250 \%$ with increasing the steel volume fraction. However, tensile strength tends to decrease after a certain limit (i.e., approximately $50 \%$ of steel volume fraction).

Figure 12 shows the stress-strain curves for the D13 specimens.

The linear stress-strain relationship of the specimens was found for Type A in Figure 12(a), and in this case no material hybridization was considered [39]. In Figure 12(b), curved or bilinear behaviors of elastic modulus with respect to corresponding strains for Types B, C, and D were found. This behavior was due to the hybridization of two different materials with different elastic modulus and tensile strength. In Figure 12(b), the maximum tensile strength for number 12 (Type D) had a salient kink around $400 \mathrm{MPa}$. This phenomenon was because the steel seemed dominant with a lower tensile strength and failed prior to GFRP.

Figure 13 shows elastic modulus and maximum tensile strength as a function of steel volume fraction by cross section 
TABLE 3: Test results for D13 FRP Hybrid Bar.

\begin{tabular}{|c|c|c|c|c|c|c|c|c|c|}
\hline \multirow{2}{*}{ Number } & \multirow{2}{*}{ Name } & \multirow{2}{*}{ Type } & \multirow{2}{*}{ Steel-to-GFRP ratio (\%) } & \multicolumn{3}{|c|}{ Elastic modulus } & \multicolumn{3}{|c|}{ Tensile strength } \\
\hline & & & & Aver. (GPa) & $\mathrm{CoV}(\%)$ & Imp. (\%) & Aver. (MPa) & $\mathrm{CoV}(\%)$ & Imp. (\%) \\
\hline 1 & KICT-D13 & \multirow{3}{*}{ A } & 0.0 & 52.1 & 9.1 & 15.9 & 1103.3 & 2.6 & 54.3 \\
\hline 2 & Aslan-D13 & & 0.0 & 47.1 & 2.2 & 4.9 & 739.4 & 2.5 & 3.4 \\
\hline 3 & V-Rod-D13 & & 0.0 & 44.9 & 7.4 & - & 714.9 & 0.7 & - \\
\hline 4 & FHB-D13-D4-B & \multirow{4}{*}{ B } & 9.2 & 76.5 & 9.1 & 70.2 & 1122.7 & 6.4 & 57.0 \\
\hline 5 & FHB-D13-D7-B & & 29.9 & 94.9 & 2.9 & 111.2 & 1269.7 & 3.3 & 77.6 \\
\hline 6 & FHB-D13-D9-B & & 51.0 & 111.1 & 5.0 & 147.3 & 1258.8 & 1.2 & 76.1 \\
\hline 7 & FHB-D13-D11-B & & 76.2 & 148.2 & 5.8 & 229.8 & 833.9 & 8.2 & 16.6 \\
\hline 8 & FHB-D13-D2-4-C & \multirow{4}{*}{$\mathrm{C}$} & 9.8 & 62.6 & 4.1 & 39.3 & 1150.3 & 2.7 & 60.9 \\
\hline 9 & FHB-D13-D2-13-C & & 31.8 & 99.8 & 3.4 & 122.2 & 1245.4 & 1.7 & 74.2 \\
\hline 10 & FHB-D13-D2-23-C & & 57.0 & 126.9 & 6.2 & 182.4 & 1323.2 & 4.9 & 85.1 \\
\hline 11 & FHB-D13-D2-29-C & & 70.3 & 157.3 & 3.0 & 250.1 & 1156.4 & 2.0 & 61.7 \\
\hline 12 & FHP-D13-D10-D & $\mathrm{D}$ & 57.2 & 110.1 & 7.2 & 144.9 & 669.5 & 3.3 & -6.3 \\
\hline
\end{tabular}

Note. Improvement (Imp.) is relative values normalized to case number 3.

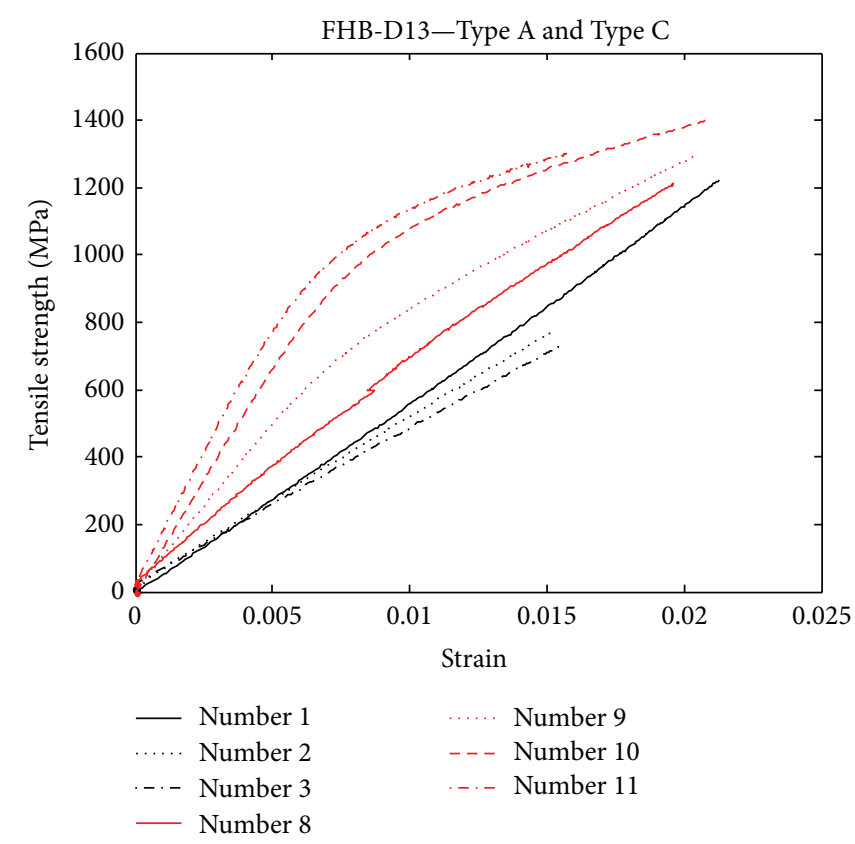

(a)

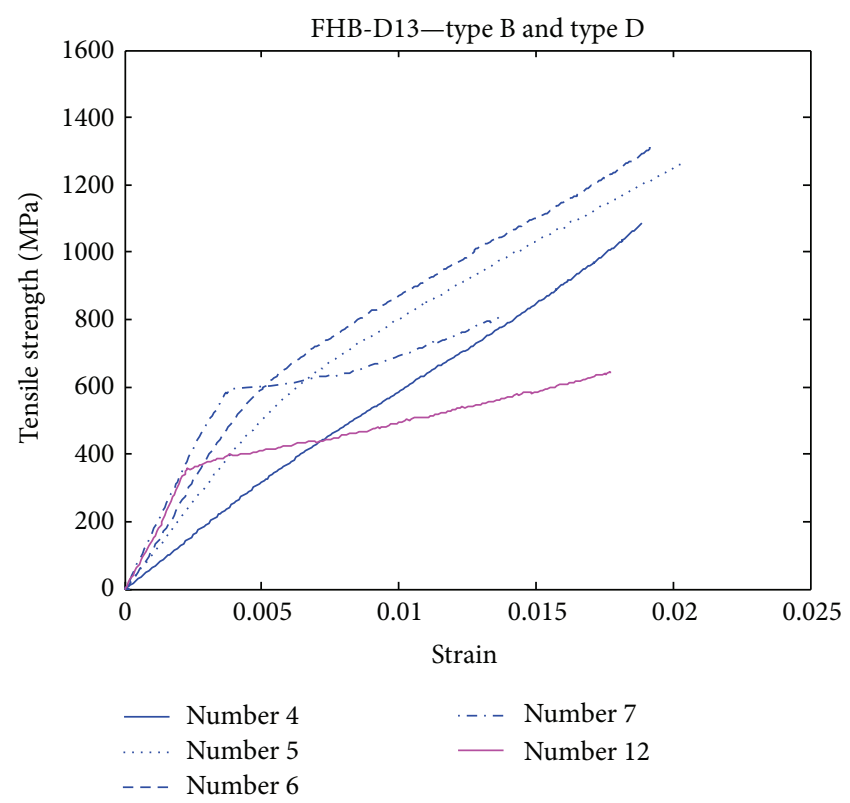

(b)

Figure 12: Stress-strain curves of D13 FRP Hybrid Bar: (a) Types A and B; (b) Type B and Type D.

area (i.e., the steel-to-GFRP volume ratio). Error bars based on standard deviations are also described. A linear increment on elastic modulus was found, and this was proportional to the steel volume fraction for Type $\mathrm{B}$ and Type $\mathrm{C}$ in Figure 13(a). For Type B and Type C, the maximum tensile strength was not much influenced by the steel volume fraction but it tended to decrease after a certain limit around 50\% of the volume fraction. Tensile strength for Type D was much lower compared to other cases.

According to the test data in the literatures, a strength reduction may occur due to damage, misplacement of fibers during the fabrication, the size of specimen, and the gripping method. For example, the tests performed by Malvar and Bish [40] on different grips like ASTM D3916 grip adapter and clamp type revealed that the tensile strength of FRP rod obtained using ASTM D3916 grip adapters was the lowest. Regarding this effect, the CoV values were investigated and the experimental values were assumed to be consistent since the $\mathrm{CoV}$ values were relatively small, less than $10 \%$ for all cases.

Table 4 summarizes the result of tensile tests for D16 FRP Hybrid Bar. Most of the specimens failed in the area of the gauge length. Seven cases were selected for tensile tests associated with 3 different types and with various steel volume fractions explained in Section 2.1.

Figure 14 plots the stress-strain curves of the D16 specimens using the load of the UTM and strain measured at the center of the rebar. 
TABLE 4: Test results for D16 FRP Hybrid Bar.

\begin{tabular}{|c|c|c|c|c|c|c|c|c|c|}
\hline \multirow{2}{*}{ Number } & \multirow{2}{*}{ Name } & \multirow{2}{*}{ Type } & \multirow{2}{*}{ Steel-to-GFRP ratio (\%) } & \multicolumn{3}{|c|}{ Elastic modulus } & \multicolumn{3}{|c|}{ Tensile strength } \\
\hline & & & & Aver. (GPa) & $\mathrm{CoV}(\%)$ & Imp. (\%) & Aver. (MPa) & $\mathrm{CoV}(\%)$ & Imp. (\%) \\
\hline 1 & KICT-D16 & $\mathrm{A}$ & 0.0 & 57.0 & 3.4 & - & 1209.5 & 2.3 & - \\
\hline 2 & FHB-D16-D2-7-C & \multirow{4}{*}{$\mathrm{C}$} & 10.9 & 58.5 & 0.5 & 2.5 & 1232.7 & 2.5 & 1.9 \\
\hline 3 & FHB-D16-D2-23-C & & 36.9 & 97.2 & 3.7 & 70.6 & 1238.6 & 1.8 & 2.4 \\
\hline 4 & FHB-D16-D2-41-C & & 60.2 & 143.3 & 3.1 & 151.4 & 1283.1 & 3.6 & 6.1 \\
\hline 5 & FHB-D16-D2-47-C & & 70.1 & 155.1 & 9.1 & 172.1 & 1361.8 & 1.3 & 12.6 \\
\hline 6 & FHP-D16-D10-D & \multirow{2}{*}{$\mathrm{D}$} & 36.6 & 100.4 & 5.5 & 76.1 & 779.5 & 2.1 & -35.6 \\
\hline 7 & FHP-D16-D13-D & & 63.2 & 146.8 & 6.9 & 157.5 & 596.5 & 2.2 & -50.7 \\
\hline
\end{tabular}

Note. Improvement (Imp.) is relative values normalized to case number 1.

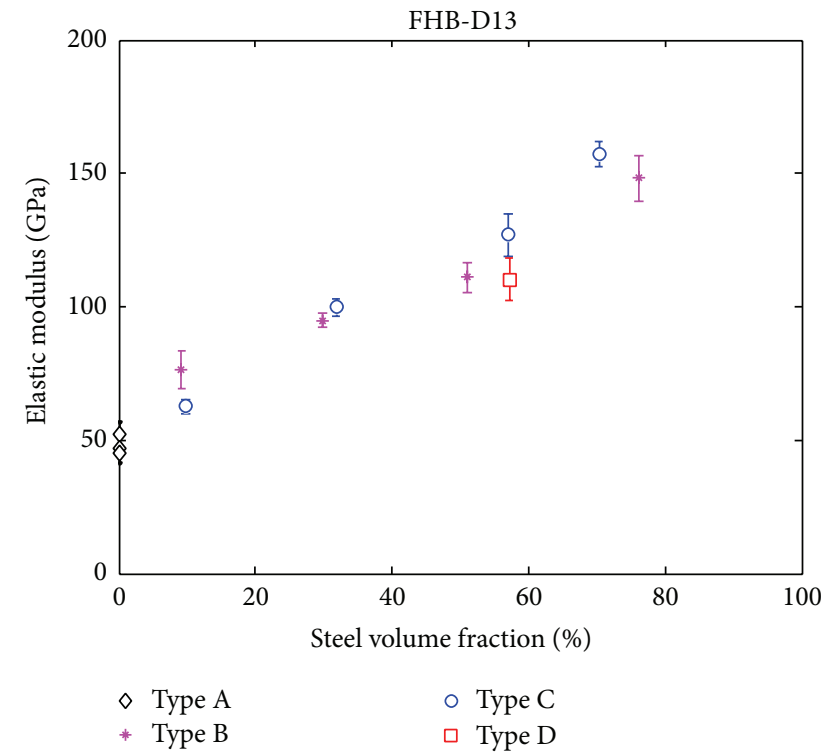

(a)

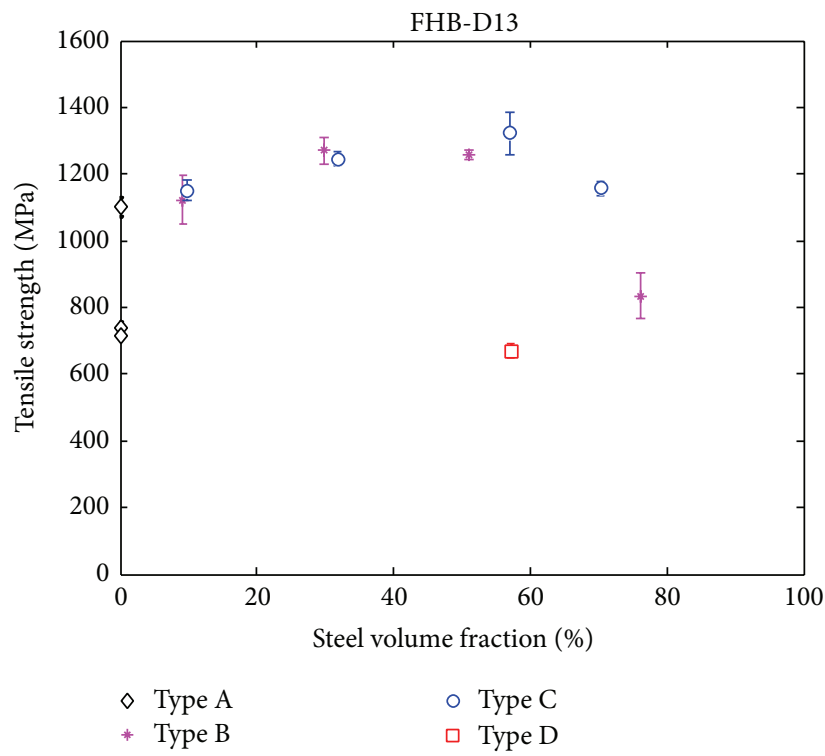

(b)

FIgURE 13: Test results for D13 FRP Hybrid Bar: (a) elastic modulus; (b) tensile strength.

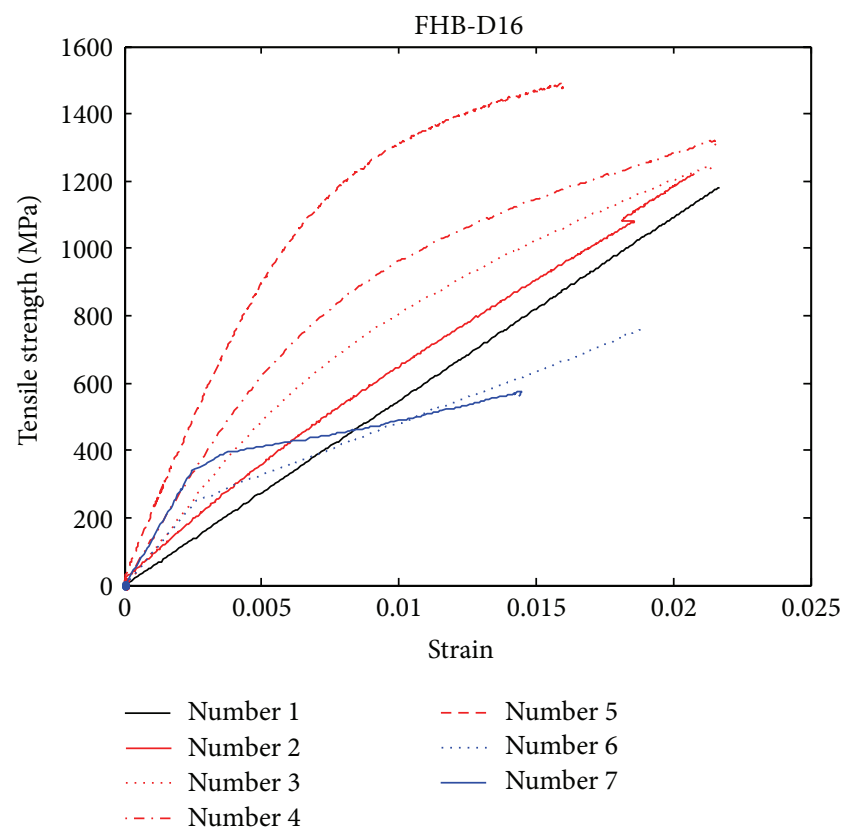

FIgURE 14: Stress-strain curves of D16 FRP Hybrid Bar.
A linear increment of elastic modulus was found, proportional to the steel volume fraction in Figure 15(a). For Type $\mathrm{C}$, a maximum tensile strength was not influenced by the steel volume fraction (until approximately 70\%) but a tensile strength for Type D was decreased with increasing the steel volume fraction.

Table 5 summarizes the result of tensile tests for D19 FRP Hybrid Bar. Most of the specimens failed in the gauge length. Seven cases were selected for tensile tests associated with 3 different types and with various steel-to-GFRP volume ratios explained in Section 2.1.

Figure 16 plots the stress-strain curves of the D19 specimens using the load of the UTM and strain measured at the center of the rebar.

In Figure 17(a) a linear increment on elastic modulus was found for Type D but the decrement was found for the case of Type C, proportional to the steel volume fraction. For both Type $\mathrm{C}$ and Type $\mathrm{D}$, a maximum tensile strength was decreased with the increasing steel volume fraction.

Brittle fracture types were noticed for GFRP bars, including Case A, Aslan 100, and V-Rod, as shown in Figures 18(a) 18(c). One of the shortcomings of GFRP was the brittle 
TABLE 5: Test results for D19 FRP Hybrid Bar.

\begin{tabular}{|c|c|c|c|c|c|c|c|c|c|}
\hline \multirow{2}{*}{ Number } & \multirow{2}{*}{ Name } & \multirow{2}{*}{ Type } & \multirow{2}{*}{ Steel-to-GFRP ratio (\%) } & \multicolumn{3}{|c|}{ Elastic modulus } & \multicolumn{3}{|c|}{ Tensile strength } \\
\hline & & & & Aver. (GPa) & $\mathrm{CoV}(\%)$ & Imp. (\%) & Aver. (MPa) & $\mathrm{CoV}(\%)$ & Imp. (\%) \\
\hline 1 & KICT-D19 & A & 0.0 & 57.7 & 6.1 & - & 932.9 & 4.8 & - \\
\hline 2 & FHB-D19-D2-23-C & & 25.0 & 90.8 & 4.9 & 57.4 & 1217.9 & 3.5 & 30.5 \\
\hline 3 & FHB-D19-D2-41-C & $\mathrm{C}$ & 42.3 & 123.2 & 3.2 & 113.4 & 1197.2 & 2.4 & 28.3 \\
\hline 4 & FHB-D19-D2-63-C & & 66.3 & 118.5 & 9.1 & 105.4 & 781.8 & 7.4 & -16.2 \\
\hline 5 & FHP-D19-D10-D & & 24.7 & 88.8 & 7.2 & 53.9 & 899.6 & 5.1 & -3.6 \\
\hline 6 & FHP-D19-D13-D & $\mathrm{D}$ & 45.9 & 120.7 & 5.6 & 109.3 & 537.7 & 11.0 & -42.4 \\
\hline 7 & FHP-D19-D16-D & & 67.9 & 148.2 & 17.3 & 156.8 & 466.6 & 4.4 & -50.0 \\
\hline
\end{tabular}

Note. Improvement (Imp.) is relative values normalized to case number 1.

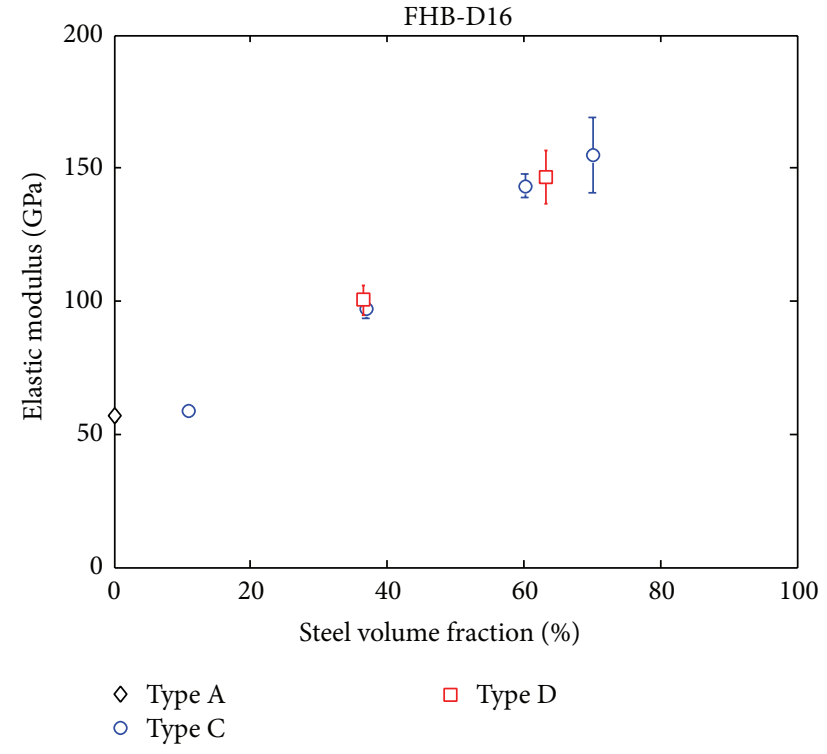

(a)

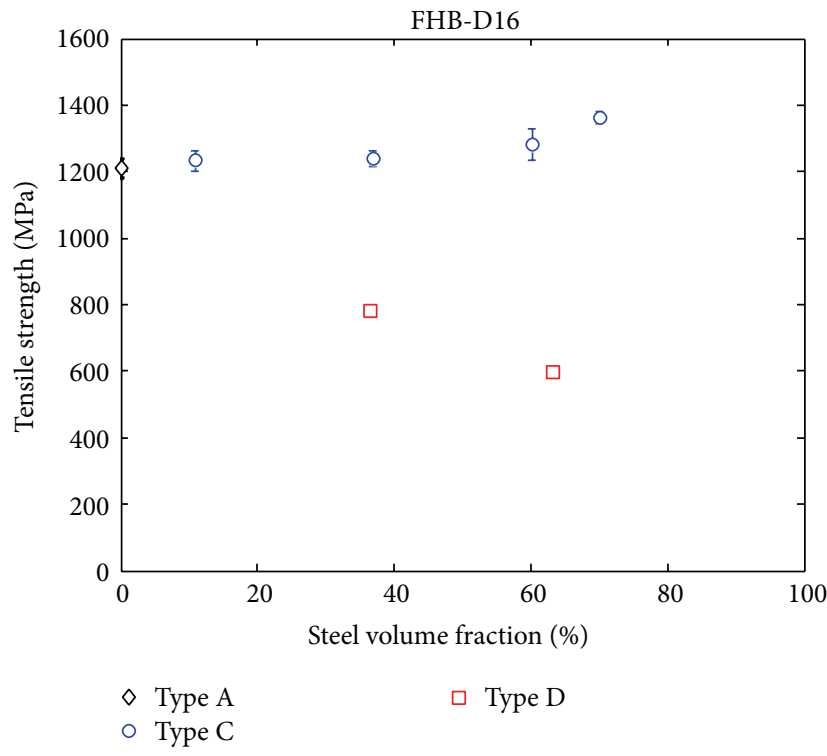

(b)

FIGURE 15: Test results for D16 FRP Hybrid Bar: (a) elastic modulus; (b) tensile strength.

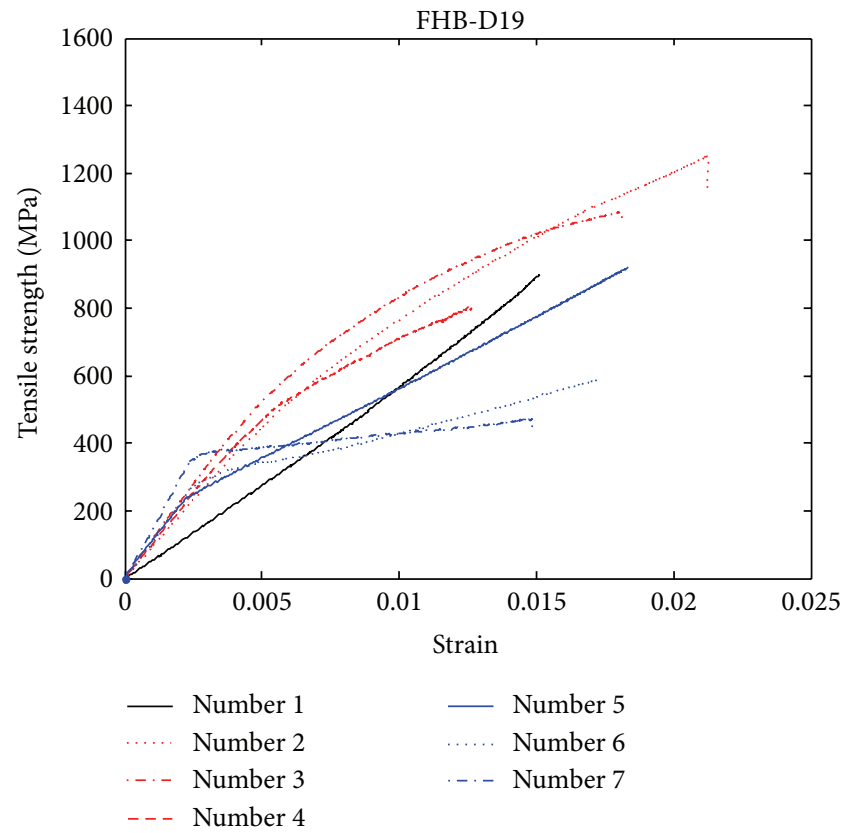

FIGURE 16: Stress-strain curves of D19 FRP Hybrid Bar. fracture, and it was confirmed that this issue could be improved by the material hybridization (i.e., "pseudoductile" behavior) proved through this study shown in Figure 18(d).

\section{Conclusions}

In this study the material hybridization of a GFRP bar is considered to overcome its low elastic modulus to use as reinforcement for concrete structures built in the corrosive environment. The existing GFRP bar developed at Korea Institute of Civil Engineering and Building Technology (KICT [25]) is hybridized with steel which has a higher elastic modulus than GFRP. Various combinations of mixing composites and the ratio of steel-to-GFRP volume fraction are investigated.

As a result of tensile test, the elastic modulus of the steel hybridized GFRP bar is increased by up to $250 \%$ with the material hybridization in comparison with the nonhybrid GFRP bar. All steel hybridized bars are all effective in increasing the elastic modulus. Most effective case in increasing tensile strength could be Type C (i.e., using steel wires) but with more complicated manufacturing process compared to other cross section types. 


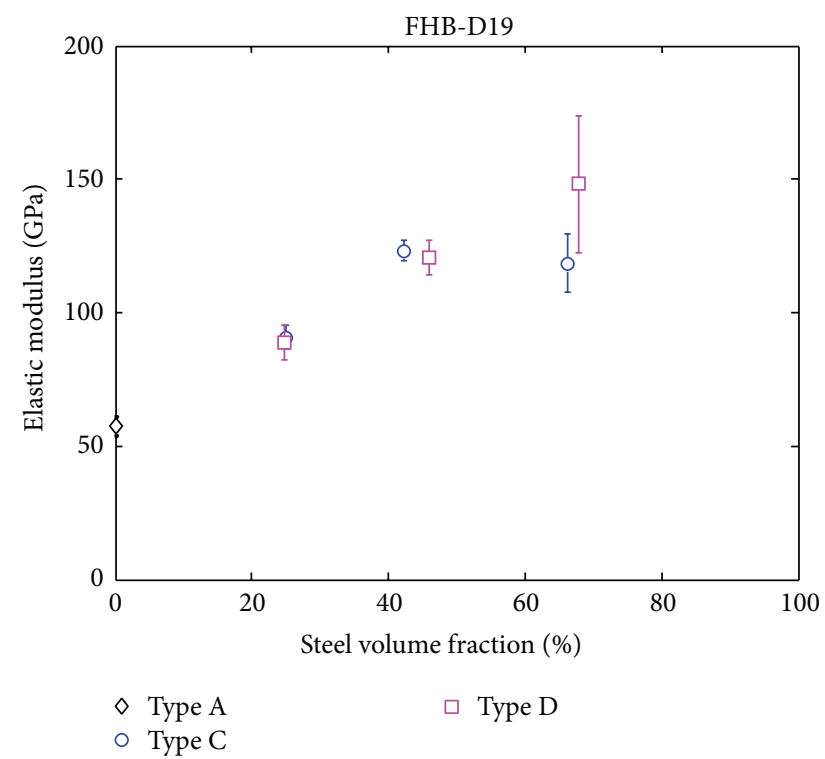

(a)

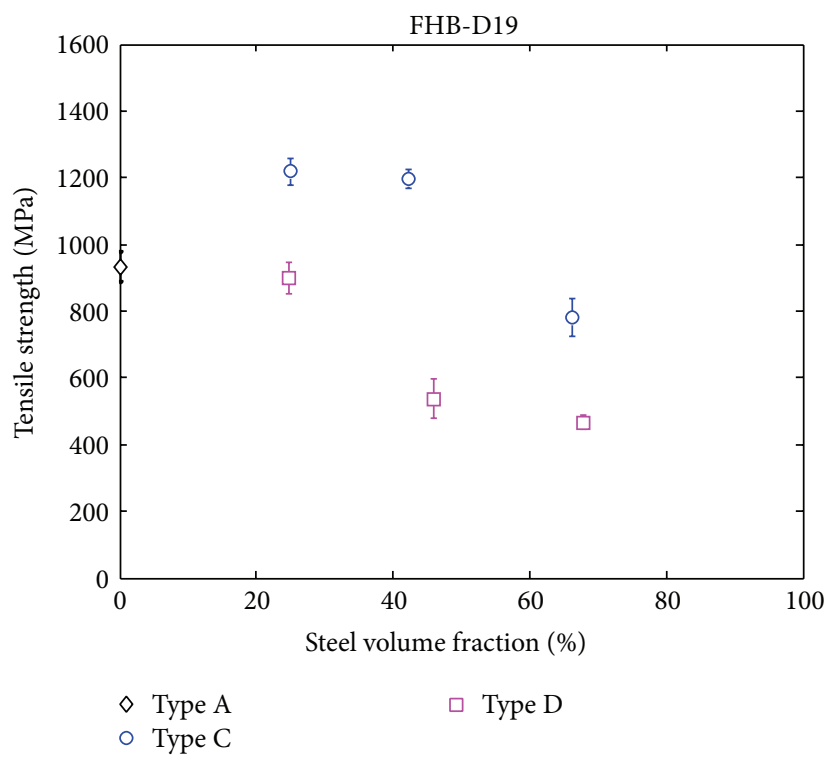

(b)

FIGURE 17: Test results for D19 FRP Hybrid Bar: (a) elastic modulus; (b) tensile strength.

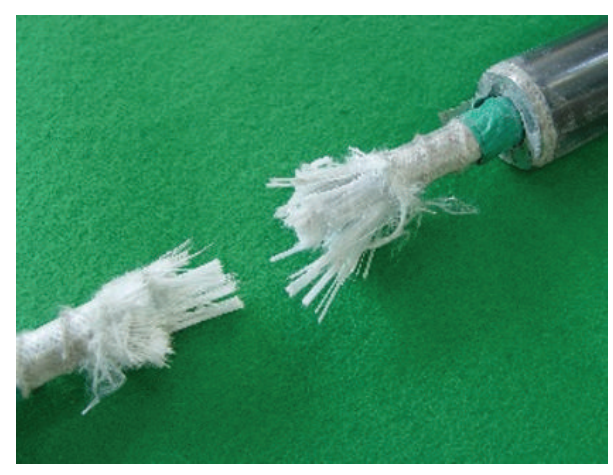

(a)

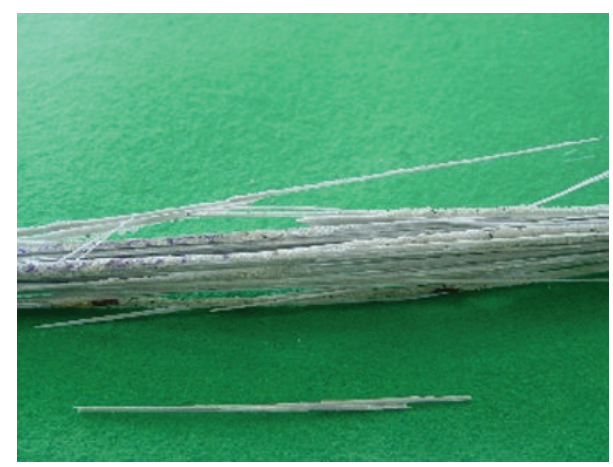

(c)

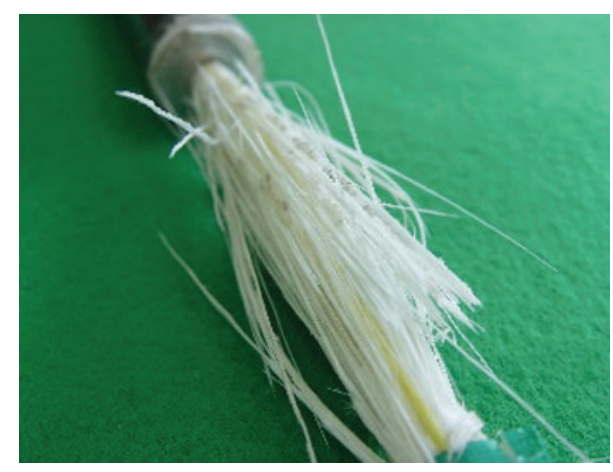

(b)

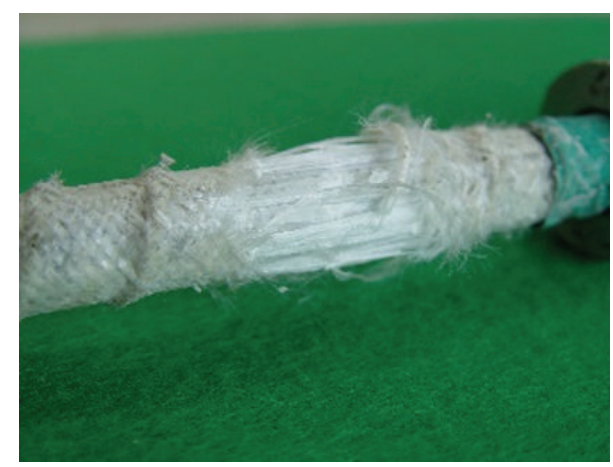

(d)

FIgURE 18: Failure modes [24]: (a) KICT bar; (b) Aslan 100; (c) V-Rod; and (d) FRP Hybrid Bar.

One of the shortcomings of the GFRP bar is a brittle fracture and this issue could be improved by the material hybridization found in this study.
Further investigation should be conducted to study the effect of the stress redistribution mechanism on the "pseudoductile" behavior regarding the quantity as well as the 
dispersion of steel. Bonding strength and corrosion protection efficiency are currently being investigated. Economic feasibility of the hybrid FRP bars should also be investigated.

\section{Disclaimer}

Any opinions, findings, and conclusions or recommendations are those of the writers and do not necessarily reflect the views of this agency.

\section{Conflict of Interests}

The authors declare that there is no conflict of interests regarding the publication of this paper.

\section{Acknowledgments}

This research (basic research: development of hybrid FRP bars for concrete waterfront structures) was supported by Korea Institute of Civil Engineering and Building Technology and funded by the Ministry of Science, ICT, and Future Planning of Korean Government.

\section{References}

[1] American Concrete Institute (ACI), "State-of-the-art report on fiber reinforced plastic (FRP) reinforcement for concrete structures," ACI 440R-96, 1996.

[2] Pultrall Inc, Product Guide Specification, 2001, http://www.pultrall.com.

[3] Korea Institute of Construction Technology (KICT), Design and Construction Technology for Concrete Structures Using Advanced Composite Materials: FRP Rebars and Grids, Korea Research Council of Public Science and Technology, 2004 (Korean).

[4] Y. J. You, K. T. Park, D. W. Seo, and J. H. Hwang, "Tensile strength of GFRP reinforcing bars with hollow section," Advances in Material Science and Engineering, vol. 2015, Article ID 621546, 8 pages, 2015.

[5] K. D. Jones and A. T. DiBenedetto, "Fiber fracture in hybrid composite systems," Composites Science and Technology, vol. 51, no. 1, pp. 53-62, 1994.

[6] G. Kretsis, "A review of the tensile, compressive, flexural and shear properties of hybrid fibre-reinforced plastics," Composites, vol. 18, no. 1, pp. 13-23, 1987.

[7] C. E. Bakis, A. Nanni, J. A. Terosky, and S. W. Koehler, "Selfmonitoring, pseudo-ductile, hybrid FRP reinforcement rods for concrete applications," Composites Science and Technology, vol. 61, no. 6, pp. 815-823, 2001.

[8] L. Taerwe, Non-Metallic (FRP) Reinforcement for Concrete Structures: Proceedings of the Second International RILEM Symposium, CRC Press, Boca Raton, Fla, USA, 1995.

[9] X. Wang and Z. Wu, "Integrated high-performance thousandmetre scale cable-stayed bridge with hybrid FRP cables," Composites Part B: Engineering, vol. 41, no. 2, pp. 166-175, 2010.

[10] X. Wang and Z. Wu, "Evaluation of FRP and hybrid FRP cables for super long-span cable-stayed bridges," Composite Structures, vol. 92, no. 10, pp. 2582-2590, 2010.

[11] X. Wang, Z. Wu, G. Wu, H. Zhu, and F. Zen, "Enhancement of basalt FRP by hybridization for long-span cable-stayed bridge," Composites Part B: Engineering, vol. 44, no. 1, pp. 184-192, 2013.
[12] G. Wu, Z.-S. Wu, Y.-B. Luo, Z.-Y. Sun, and X.-Q. Hu, "Mechanical properties of steel-frp composite bar under uniaxial and cyclic tensile loads," ASCE Journal of Materials in Civil Engineering, vol. 22, no. 10, Article ID 010010QMT, pp. 1056-1066, 2010.

[13] Z. S. Wu, Y. X. Shao, K. Iwashita, and K. Sakamoto, "Strengthening of preloaded RC beams using hybrid carbon sheets," Journal of Composites for Construction, vol. 11, no. 3, pp. 299-307, 2007.

[14] Z. Wu, X. Wang, K. Iwashita, T. Sasaki, and Y. Hamaguchi, "Tensile fatigue behaviour of FRP and hybrid FRP sheets," Composites Part B: Engineering, vol. 41, no. 5, pp. 396-402, 2010.

[15] T. C. Rousakis, K. B. Kouravelou, and T. K. Karachalios, "Effects of carbon nanotube enrichment of epoxy resins on hybrid FRP-FR confinement of concrete," Composites Part B: Engineering, vol. 57, pp. 210-218, 2014.

[16] T. C. Rousakis, "Hybrid confinement of concrete by FRP sheets and fiber ropes under cyclic axial compressive loading," ASCE Journal of Composites for Construction, vol. 17, no. 5, pp. 732-743, 2013.

[17] A. Nanni, T. Okamoto, M. Tanigaki, and S. Osakada, "Tensile properties of braided FRP rods for concrete reinforcement," Cement and Concrete Composites, vol. 15, no. 3, pp. 121-129, 1993.

[18] A. Nanni, M. J. Henneke, and T. Okamoto, "Tensile properties of hybrid rods for concrete reinforcement," Construction and Building Materials, vol. 8, no. 1, pp. 27-34, 1994.

[19] A. Nanni, M. J. Henneke, and T. Okamoto, "Behaviour of concrete beams with hybrid reinforcement," Construction and Building Materials, vol. 8, no. 2, pp. 89-95, 1994.

[20] M. M. S. Cheung and T. K. C. Tsang, "Behaviour of concrete beams reinforced with hybrid FRP composite rebar," Advances in Structural Engineering, vol. 13, no. 1, pp. 81-93, 2010.

[21] J.-P. Won, C.-G. Park, S.-J. Lee, and B.-T. Hong, "Durability of hybrid FRP reinforcing bars in concrete structures exposed to marine environments," International Journal of Structural Engineering, vol. 4, no. 1-2, pp. 63-74, 2013.

[22] J.-P. Won and C.-G. Park, "Effect of environmental exposure on the mechanical and bonding properties of hybrid FRP reinforcing bars for concrete structures," Journal of Composite Materials, vol. 40, no. 12, pp. 1063-1076, 2006.

[23] J.-P. Won, C.-G. Park, and C.-I. Jang, "Tensile fracture and bond properties of ductile hybrid FRP reinforcing bars," Polymers and Polymer Composites, vol. 15, no. 1, pp. 9-16, 2007.

[24] D. W. Seo, K. T. Park, Y. J. You, and J. H. Hwang, "Evaluation for tensile performance of recently developed FRP hybrid bars," International Journal of Emerging Technology and Advanced Engineering, vol. 4, no. 6, pp. 631-637, 2014.

[25] Korea Institute of Construction Technology (KICT), http:// www.kict.re.kr/.

[26] Y.-J. You, Y.-H. Park, H.-Y. Kim, and J.-S. Park, "Hybrid effect on tensile properties of FRP rods with various material compositions," Composite Structures, vol. 80, no. 1, pp. 117-122, 2007.

[27] ASLAN, http://www.aslanfrp.com/.

[28] V-Rod, http://www.vrod.ca.

[29] A. L. Kalamkarov, A. V. Georgiades, D. O. MacDonald, and S. B. Fitzgerald, "Pultruded fibre reinforced polymer reinforcements with embedded fibre optic sensors," Canadian Journal of Civil Engineering, vol. 27, no. 5, pp. 972-984, 2000.

[30] ISIS Canada, Design Manual 3: Reinforcing Concrete Structures with Fiber Reinforced Polymers, The Canadian Network of Centers of Excellence on Intelligent Sensing for Innovative Structures, 2001. 
[31] Z. Wang, Y. Goto, and O. Joh, "Bond strength of various types of fiber reinforced plastic rods," in Proceedings of the 4th International Symposium on Fiber Reinforced Polymer Reinforcement for Reinforced Concrete Structures, Baltimore, Md, USA, October 1999.

[32] F. K. Ko, W. Somboonsong, and H. G. Harris, "Fiber architecture based design of ductile composite rebars for concrete structures," in Proceedings of the 11th International Conference of Composite Materials, Gold Coast, Australia, 1997.

[33] M. S. Ahmadi, M. S. Johari, M. Sadighi, and M. Esfandeh, "An experimental study on mechanical properties of GFRP braidpultruded composite rods," eXPRESS Polymer Letters, vol. 3, no. 9, pp. 560-568, 2009.

[34] Korea Institute of Construction Technology (KICT), Design and Construction Technology for Concrete Structures Using Advanced Composite Materials, Korea Institute of Construction Technology (KICT), Goyang, South Korea, 2006 (Korean).

[35] Owens Corning, http://www.owenscorning.co.kr/.

[36] ASTM, "Standard test method for tensile properties of pultruded glass-fiber-reinforced plastic rods," ASTM D3916, 2002.

[37] CSA, Test Method for Tensile Properties of FRP Reinforcement, Canadian Standard Association, Ontario, Canada, 2002.

[38] CSA, "Design and construction of building structures with fibre-reinforced polymers," CAN/CSA S806-12, Canadian Standards Association, National Standard of Canada, 2012.

[39] D. W. Seo, K. T. Park, Y. J. You, and H. Y. Kim, "Enhancement in elastic modulus of GFRP bars by material hybridization," Engineering, vol. 5, no. 11, pp. 865-869, 2013.

[40] L. Malvar and J. Bish, "Grip effects in tensile testing of FRP bars, nonmetallic (FRP) reinforcement for concrete structures," in Proceedings of the International RILEM Symposium, pp. 108115, Ghent, Belgium, August 1995. 

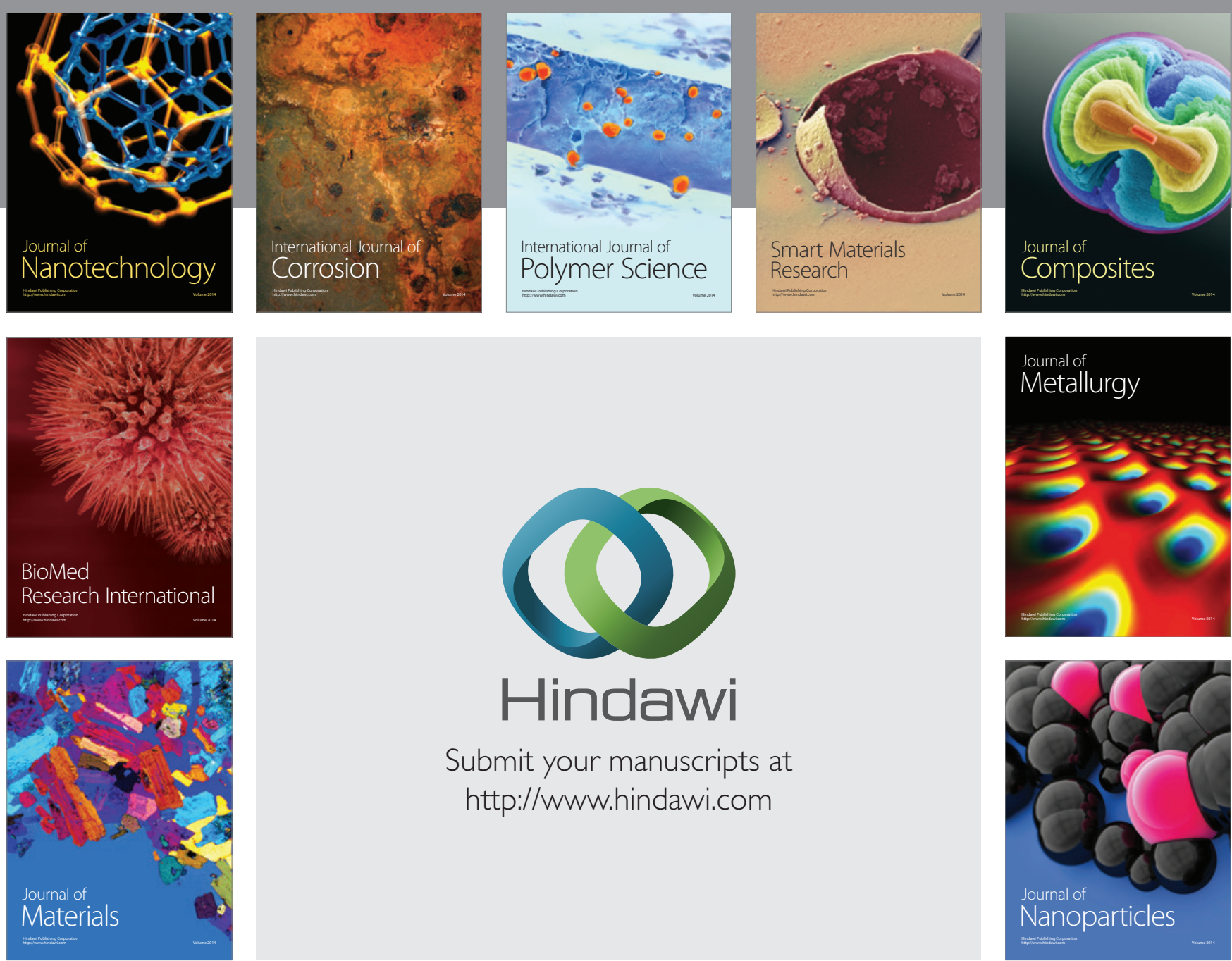

\section{Hindawi}

Submit your manuscripts at

http://www.hindawi.com

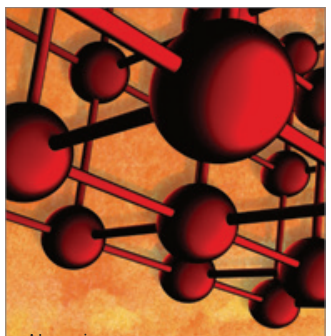

Materials Science and Engineering
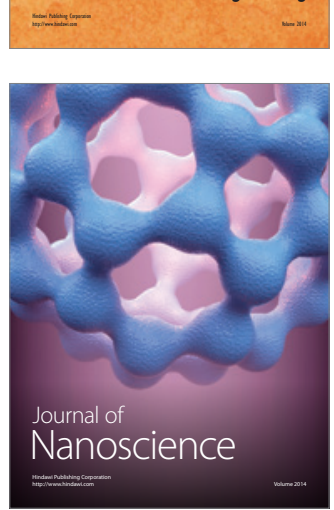
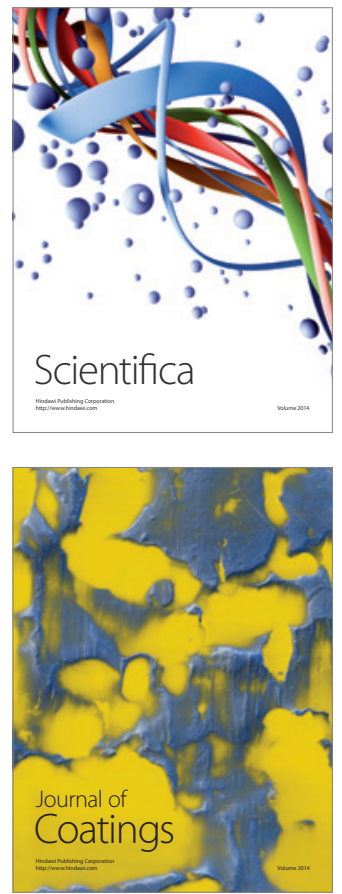
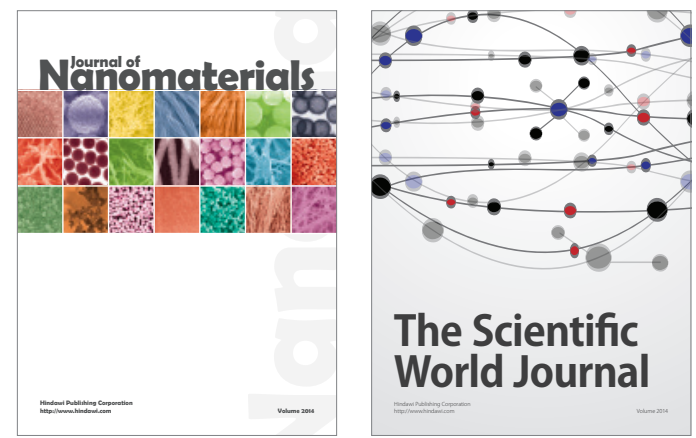

The Scientific World Journal
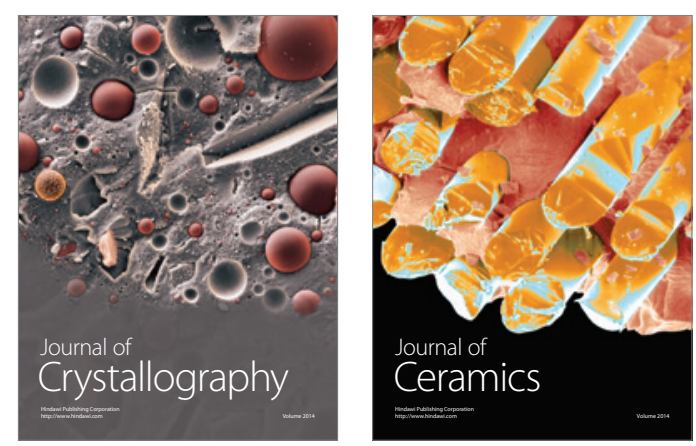
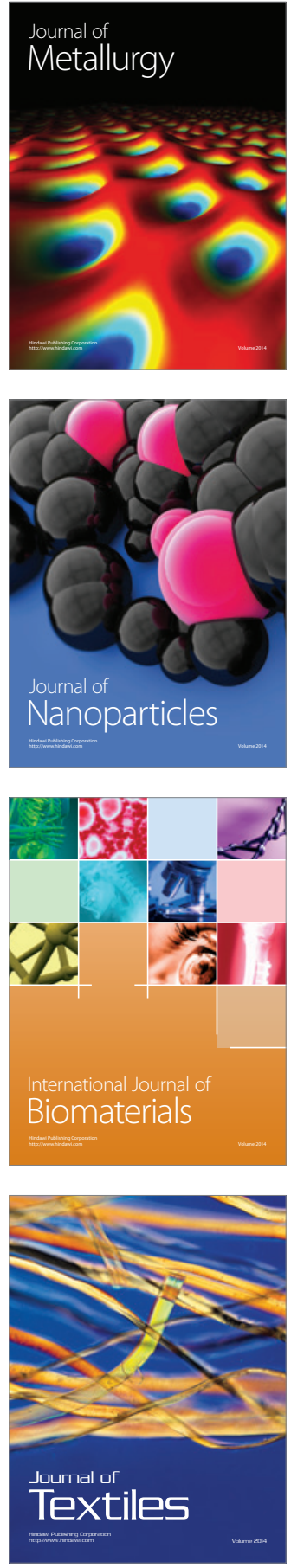